\title{
An Analytical Study of Spending on Red Meat in the Urban and Rural Areas of Fayoum Governorate
}

\author{
Yehia M.M. Khalil, Nagwa M. El-agroudy, Fatima A. Shafiq and Soheir Mokhtar
}

Department of Agricultural Economy, Agricultural and Biological Research Division, National Research Centre, 33 El Buhouth St., 12622 Dokki, Giza, Egypt

Received: 24 March 2020 / Accepted 28 May 2020 / Publication date: 10 June 2020

\begin{abstract}
Red meat conspicuously represents one of the most important sources of animal protein for the Egyptian consumer. Besides, the relative importance of calories from animal protein to the Egyptian citizen is about $4.8 \%$, while its counterpart in some developed countries is about $31 \%$. The consumer suffers from unbalance in terms of health. This is due to his relatively more dependence on vegetable protein. The research problem lies in increasing the rates of red meat consumption year after year as a result of the forced increase in the population. This is in addition to the small production of red meat, which led to widening the gap between production and consumption. The research aimed at studying the development of production and consumption, the average per capita share, the percentage of selfsufficiency and the size of the food gap of red meat during the period (2000-2018) as well as studying the agreement function of the study sample at different income levels. The study relied on the secondary data collected from the Central Agency for Public Mobilization and Statistics and the Ministry of Agriculture. Besides, it depends mainly on the primary data collected through the questionnaire form for a random sample consisting of 312 families from Fayoum Governorate distributed as follows 147 families from the urban in Fayoum Center and 165 families from the rural in Fayoum Center in 2019. The study showed an increase in both production and consumption. Besides, the average share per capita of red meat had a statistically significant increase estimated at $14.6,36.8$ thousand tons, $0.151 \mathrm{~kg} /$ year respectively during the study period (2000-2001), while the rate of self-sufficiency achieved an annual statistically significant decrease of about $1.1 \%$. Moreover, a random sample consisting of 312 families from Fayoum Governorate distributed as follows 147 families from the urban in Fayoum Center and 165 families from the rural in Fayoum Center in 2019. The sample was divided into three categories according to the family income, the first category is less than (2000 pounds), the second category (2000-4000 pounds), third category (more than 4000 pounds). The Stage Regression is used in the bi-logarithmic form to determine the most important factors affecting spending on red meat in the study sample in the urban and rural of different income categories at Fayoum. The results indicated that there is a direct relationship between the families's spending on red meat, the average monthly family income, the number of family members, and an inverse relationship with the price of meat in the countryside and urban areas. Finally, red meat is a luxury item especially in low-income families.
\end{abstract}

Keywords: red meat production, consumption of red meat, consumption spending.

\section{Introduction}

Red meat conspicuously represents one of the most important sources of animal protein for the Egyptian consumer. Besides, the relative importance of calories from animal protein to the Egyptian citizen is about $4.8 \%$, while its counterpart in some developed countries is about $31 \%$. Moreover, the relative importance of calories derived from grains to the Egyptian citizen is about $60.5 \%$, while its counterpart in developed countries is about $19.7 \%$. Although the total share of the Egyptian citizen's calories is close to its counterpart in developed countries, he suffers from unbalance in terms of health due to his relatively more dependence on vegetable protein.

\section{Problem of the Study}

The research problem lies in increasing the rates of red meat consumption year after year as a result of the forced increase in the population. This is in addition to the small production of red meat,

Corresponding Author: Nagwa M. El-agroudy, Field Crops Research Dept., National Research Centre, 33 El Buhouth St., 12622 Dokki, Giza, Egypt. E-mail: nagwa_agroudy@hotmail.com 
which led to widening the gap between production and consumption and thus a decrease in the average per capita share of them from the global rates recommended by international organizations. Therefore, it requires the necessity of identifying the most important determinants of red meat production and its demand

\section{Objective of the Study}

Based on the problem of the study, its objective was determined in identifying the reasons for the low average per capita share of red meat through:

Studying the development of production and consumption, the average per capita share, the percentage of self-sufficiency and the size of the food gap of red meat during the period (2000-2018) as well as studying the agreement function of the study sample at different income levels.

\section{Methodology of the Study and Data Sources}

The study used the descriptive analysis approach in describing the problem in addition to the quantitative analysis using some different scales such as the general direction that was used in studying the development of some productive and consumer indicators of the commodity under study. This is in addition to the multiple regressions used in estimating each of the spending functions of the study sample.

Moreover, the study relied on the secondary data collected from the Central Agency for Public Mobilization and Statistics and the Ministry of Agriculture. Besides, it depends mainly on the primary data collected through the questionnaire form for a random sample consisting of 312 families from Fayoum Governorate distributed as follows 147 families from the urban in Fayoum Center and 165 families from the rural in Fayoum Center in 2019.

\section{Evolution of Some of the Production and Consumption Indicators of Red Meat in the Arab Republic of Egypt}

Red meat is one of the most important sources of animal protein. Consequently, it receives the state attention to provide it, whether by increasing the efficiency and productivity of the resources used in its production or encouraging investments in the field of its production requirements to fill production deficiencies in meeting local consumption requirements and the continuous decline in the average per capita share of them from the global standard rates. It reached about $14.9 \mathrm{~kg} /$ year as an average for the study period.

\section{First: Amount of Production and Consumption, Average per Capita and Self-sufficiency of Red Meat in Egypt}

Through studying the amount of red meat production at the national level during the period (2000-2018), it was shown that it ranged between two levels, a minimum of about 672 thousand tons in 2000, and a maximum of about 1030 thousand tons in 2018 with an increase of about $53.3 \%$. This is in addition to the estimate of the general time direction equation for production during the study period. A statistically significant annual increase estimated at 14.6 thousand tons, representing about $1.62 \%$ of the average amount of production, estimated at 898 thousand tons, as shown in Table (1).

As for the consumption of red meat at the national level, it ranged between a minimum of about 782 thousand tons in 2000, and a maximum of about 1506 thousand tons in 2018, with an increase representing about $92.6 \%$, and with an estimate of the general time direction of red meat consumption during the study period (2000-2018). The statistically significant annual increase is estimated at 36.8 thousand tons, representing about $3.1 \%$ of the average consumption, estimated at 1175 thousand tons, as shown in Table (1).

The average per capita share of red meat at the national level ranged between a minimum of about $12.1 \mathrm{~kg} /$ year in 2001, and a maximum of about $19.05 \mathrm{~kg} /$ year in 2015 . This is in addition to an increase representing about $57.4 \%$, and an estimate of the general time direction equation for the average per capita of red meat during the study period (2000-2018). The annual statistically significant increase estimated at $0.151 \mathrm{~kg} /$ year, represents about $1.01 \%$ of the average study period, estimated at $14.9 \mathrm{~kg} /$ year, as shown in Table (1).

Moreover, the percentage of self-sufficiency in red meat ranged between a minimum of about $57.6 \%$ in 2015 , and a maximum of about $88.8 \%$ in 2009 . This is in addition to an increase of about 
$51 \%$ over the minimum, and by estimating the general time direction equation for self-sufficiency of red meat during the study period (2000-2018), the significant annual deficiency is statistically significant, estimated at $1.1 \%$, representing about $1.5 \%$ of the average study period, estimated at $77.9 \%$, as shown in Table (1).

Table 1: Equations of the General Time Direction of the Amount of Production, Consumption, and Self-sufficiency of Red Meat during the Period (2000-2018)

\begin{tabular}{llccc}
\hline Indices & Equation & $\mathbf{R}^{2}$ & Average & Rate of Change \\
\hline Production (Thousand Tons) & $\begin{array}{l}\mathrm{Y}^{\wedge}=752+14.6 \\
\mathrm{Xi} .(4.6)^{* *}\end{array}$ & 0.56 & 898 & 1.62 \\
Consumption (Thousand Tons) & $\begin{array}{l}\mathrm{Y}^{\wedge}=807+36.8 \\
\mathrm{Xi}(7.6)^{* *}\end{array}$ & 0.77 & 1175 & 3.1 \\
$\begin{array}{l}\mathrm{Y}^{\wedge}=13.4+0.151 \\
\text { Individual's Share (kg / year) }\end{array}$ & $\begin{array}{l}\mathrm{Xi}(2.4)^{*} \\
\mathrm{Y}^{\wedge}=89.3-1.1 \\
\mathrm{Xi}(4.3-)^{* *}\end{array}$ & 0.26 & 149 & 1.01 \\
Self-sufficiency \% & 0.52 & 77.9 & 1.5 \\
\hline
\end{tabular}

Where $\mathrm{Y}^{\wedge}=$ indicates the estimated value of the dependent variable,

$\mathrm{Xi}=$ denotes the time element as an independent variable where $\mathrm{i}(1,2,3,4 \ldots 19)$

** Significant at level of $1 \%$

Source: Ministry of Agriculture - Central Administration for Agricultural Economics - Food Balance Bulletin various Editions.

Second: Study Sample, Family Income, Individual Consumption, and Spending on Red Meat

Through studying the sample of the study that was randomly selected from the urban and rural areas of Fayoum Center in Fayoum Governorate, because Fayoum Center is one of the largest centers in the population, 312 families were divided into 147 families as urban, representing about $47.1 \%$, and 165 families representing $52.9 \%$ as rural. Moreover, the monthly income of the family was chosen. Consequently, the first category was (less than 2000 pounds), the second category was (2000-4000 pounds), and the third one was (more than 4000 pounds). Besides, the number of urban families was $30,80,37$ for the 3 categories, respectively, while the number of families in the countryside was 35 , 85 , and 45 families for the 3 categories, respectively. The average monthly income of the family for the three categories in urban areas is about $1253,2670,5540$ pounds for the three categories, while the average monthly income of a rural family is about 1137, 2450, 5216 pounds for the three groups, respectively. Additionally, the average number of individuals in families for the three urban groups is about 5, 5, 4 individuals, while the average number of individuals in the family in the countryside is about seven, 6 , and 5 individuals, respectively.

Table (2) shows that the monthly per capita consumption of red meat in the three sample categories is about $0.750,1.083$ and $1,500 \mathrm{~kg} /$ month, respectively, while in the countryside it is about $0.667,1.00$, and $1,250 \mathrm{~kg} /$ month, respectively. The increase in urban over rural is represented by about $11.1 \%, 7.7 \%$, and $16.7 \%$ for the 3 categories, respectively.

Table 2: Selected Sample in the Urban and Rural Areas of Fayoum, Per Capita Consumption, Consumer Prices, Household Income, and Monthly Spending on Red Meat, Poultry, and Fish

\begin{tabular}{lcccccc}
\hline Statement & \multicolumn{2}{c}{$\begin{array}{c}\text { First } \\
\text { category }\end{array}$} & \multicolumn{2}{c}{$\begin{array}{c}\text { Second } \\
\text { category }\end{array}$} & \multicolumn{2}{c}{$\begin{array}{c}\text { Third } \\
\text { category } \\
\text { Rural }\end{array}$} \\
& Urban & Rural & Urban & Rural & Urban & Rural \\
\hline Number of Families & 30 & 35 & 80 & 85 & 37 & 45 \\
Number of Family Members & 5 & 7 & 5 & 6 & 4 & 5 \\
Monthly Family Income & 1853 & 1537 & 3670 & 3150 & 6550 & 5218 \\
Individual's Share of Red Meat kg / Month & 0.750 & 0.667 & 1.083 & 1.000 & 1.500 & 1.250 \\
Red Meat Price kg / Pound & 100 & 80 & 115 & 110 & 125 & 110 \\
Poultry Price kg / Pounds & 33 & 26 & 35 & 30 & 40 & 35 \\
Fish Price kg / Pounds & 30 & 25 & 40 & 35 & 50 & 40 \\
Spending on Red Meat per Pound & 375.0 & 353.3 & 663.0 & 600.0 & 750.0 & 687.5 \\
\hline
\end{tabular}

Source: Collected and Calculated from the Data of the Study Sample in Fayoum Governorate in 2019 
The price of the kilogram of meat in the three urban categories was about 100,115,125 pounds and reached about 80, 110, and 110 pounds in the countryside of the sample for the three groups, respectively. It became obviously clear from the study that the first category of imported meat was preferred because their prices match with their income.

The Monthly spending of the family on red meat in the three sample groups, which amounts to about $375,663,750$ pounds / month, while in the countryside it is about $353.3,600$, and 687.5 pounds / month, respectively. The increase in urban over rural is represented by $5.8 \%, 9.5 \%, 8.3 \%$, respectively as shown in Table (2).

\section{Third: Factors Affecting Consumption Spending on Red Meat of the Study Sample}

This part of the research comprises a study of the factors affecting the consumption of red meat. Besides, income is one of the most important factors along with the price of the commodity and the prices of alternative goods. These factors differ from one person to another and from one society to another.

\section{Factors Affecting Consumer Spending in the Urban and Rural Areas of the Sample}

Through studying the relationship between consumers spending on meat $(\mathrm{Y})$, as a dependent factor, and the independent and influencing factors, namely; the number of family members (X1), the price of red meat (X2), poultry price (X3), fish price (X4), and the monthly income of the family head (X5). The Stage Regression is used in the bi-logarithmic form to determine the most important factors affecting spending on red meat in the study sample in the urban and rural of different income categories at Fayoum.

\section{1- Consumer Spending on Red Meat in the First Urban and Rural Category (Less than 2000 Pounds):}

Estimates of the function shown in Table (3) indicated the positive and statistically significant relationship between the monthly spending on red meat in Fayoum urban region, first category of the study sample and the number of family members (X1), the price of a kilogram of fish (X4), the monthly income in pounds (X5). Besides, the spending flexibility was estimated at about 1.1, 0.291, and 0.85 , respectively. It means that spending on red meat increases with an increase in the number of family members, the price of a kilogram of fish, and monthly income. Moreover, it was observed that the relationship between spending on red meat and income indicates that red meat for the first category is a luxury good because of the family's low monthly income. The value of determining coefficient is approximately 0.87 shows that $87 \%$ of the changes are in consumer spending on red meat due to the described independent factors. Therefore, the statistical significance of the estimated pattern was valid at a significant level of 0.01 as the value of calculated (F) was about 77.6.

Table 3: Stage Regression Equations for the Most Important Factors Affecting Spending on Red Meat in the Three Income Categories in the Urban and Rural Areas of Fayoum Governorate of the Study Sample in 2019

\begin{tabular}{|c|c|c|c|c|}
\hline Meat Kind & Statement & Mathematical Equation & $\mathbf{R}^{2}$ & $\mathbf{F}$ \\
\hline \multirow{2}{*}{$\begin{array}{l}\text { First } \\
\text { Category }\end{array}$} & Urban & 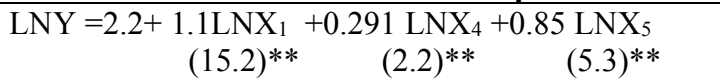 & 0.87 & 77.6 \\
\hline & Rural & $\begin{array}{cc}\mathrm{LNY}=1.4+0.96 \mathrm{LNX}_{1}+0.112 \mathrm{LNX}_{2}+0.84 \mathrm{LNX}_{5} \\
(17)^{* *} & (2.1)^{*} \\
(6.7)^{* *}\end{array}$ & 0.90 & 179 \\
\hline \multirow{2}{*}{$\begin{array}{l}\text { Second } \\
\text { Category }\end{array}$} & Urban & 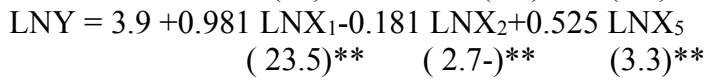 & 0.86 & 226 \\
\hline & Rural & $\begin{array}{c}\mathrm{LNY}=5.8+0.962 \mathrm{LNX}_{1}+0.384 \mathrm{LNX}_{2}+0.161 \mathrm{LNX}_{5} \\
(31)^{* *} \quad(3.7)^{* *} \\
(2.5)^{* *}\end{array}$ & 0.87 & 369 \\
\hline \multirow{2}{*}{$\begin{array}{l}\text { Third } \\
\text { Category }\end{array}$} & Urban & $\begin{array}{c}\mathrm{LNY}=2.8+1.05 \mathrm{LNX}_{1}+0.243 \mathrm{LNX}_{5} \\
(136)^{* *} \quad(2.4)^{* *}\end{array}$ & 0.89 & 97 \\
\hline & Rural & $\begin{aligned} \mathrm{LNY} & =6.8+0.859 \mathrm{LNX}_{1}-0.33 \mathrm{LN} \mathrm{X}_{2} \\
(9.5)^{* *} & (2.4)^{* *}\end{aligned}$ & 0.81 & 121 \\
\hline
\end{tabular}

Source: Collected and Calculated from the Data of the Study Sample in Fayoum Governorate in 2019.

$(* *)$ Significant at level of significance 0.01

(*) Significant at level of significance 0.05 .

The value in parentheses indicates the value of calculated $(\mathrm{T})$. 
As for the rural of the first category in the study sample (less than 2000 pounds), the estimates of the function shown in table (3) indicate a direct and statistically significant relationship between monthly spending on red meat in the countryside of the first category in the study sample in Fayoum and the number of family members (X1). This is in addition to the price per kilogram of Poultry (X3), and monthly income (X5). The spending flexibility was estimated at $0.96,0.112$, and 0.84 , respectively, which means that spending on red meat increases with the increase in the number of family members, the price of a kilogram of poultry, and monthly income. It was also noted that the relationship is positive between spending on red meat and the income. Consequently, it indicates that red meat for the first category in Fayoum countryside is considered a luxury item, and the value of the determining coefficient of about 0.90 indicates that $90 \%$ of the changes in consumer spending on red meat are due to the independent factors shown in the equation. This has proven the statistical significance of the estimated model at the level of significance 0.01 where the value of calculated $(\mathrm{F})$ was about 179 .

\section{2- Consumer Spending on Red Meat in the Second Urban and Rural Category (2000- 4000 pounds):}

Estimates of the function shown in Table (3) indicate the positive and statistically significant relationship between monthly spending on red meat in Fayoum urban in the second category of the study sample and the number of family members (X1). This is in addition to monthly income in pounds (X5), where spending flexibility was estimated at about 0.981 , and 0.252 respectively. It means that spending on red meat increases with the increase in the number of family members and monthly income. Besides, it was observed that the positive relationship between spending on red meat and income indicates that red meat for the second category is a luxury good due to the low monthly income of the family, and the reverse relationship between spending on red meat and the price of a kilogram of red meat (X2). It also means that the lower the price of red meat, the higher the spending on it, and the value of the determination factor of about 0.86 indicates that $86 \%$ of the changes in consumer spending on red meat are due to the shown independent factors. The statistical significance of the estimated model was proven at the level of significance 0.01 , where the calculated value of $(\mathrm{F})$ reached about 226 .

As for the rural of the second category in the study sample (2000-4000 pounds), the estimates of the function shown in table (3) indicate the positive and statistically significant relationship between the monthly spending on red meat in the rural category and both the number of family members (X1) and the price of poultry (X3). Additionally, spending flexibility was estimated by about 0.962 and 0.161 , respectively. It means that spending on red meat increases with the increase in the number of family members, and the price of poultry. The inverse relationship between spending on red meat and the price of a kilogram of red meat (X2) was also shown, which means that the lower the price of red meat, the higher spending on red meat. The value of determining coefficient is approximately 0.87 indicates that $87 \%$ of the changes in consumer spending on red meat are due to the shown independent factors. This has proven the statistical significance of the estimated model at the level of significance 0.01 where the calculated value of $(\mathrm{F})$ reached about 369 .

\section{3- Consumer Spending on Red Meat in the Third Urban and Rural Category (4000 pounds or more):}

Estimates of the function shown in Table indicate the positive and statistically significant relationship between the monthly spending on red meat in the Fayoum urban for the third category in the study sample and the number of family members (X1). This is in addition to the monthly income in pounds (X5), where the spending flexibility was estimated at about 1.05 , and 0.243 , respectively. It means that spending on red meat increases with the increase in the number of family members and monthly income. Besides, it was observed that the positive relationship between spending on red meat and income indicates that red meat for the third category is a luxury item due to the decrease in the monthly income of the family with the increase in the number of individuals. The value of determining coefficient is approximately 0.89 that $89 \%$ of the changes in consumer spending on red meat due to the described independent factors. Therefore, the statistical significance of the estimated pattern was valid at a significant level of 0.01 as the value of calculated (F) was about 97. 
As for the rural of the third category in the study sample (4000 pounds or more), the estimates of the equation shown in table (3) indicate the positive and statistically significant relationship between the monthly spending on red meat in the third category in the study sample in Fayoum and number of family members (X1). Additionally, spending flexibility was estimated by about 0.859 . It means that spending on red meat increases with the increase in the number of family members. The inverse relationship between spending on red meat and the price of a kilogram of red meat (X2) was also shown. The spending flexibility was estimated by about 0.33 , which means that with a decrease in price, spending on meat increases. The value of determining coefficient is approximately 0.81 indicates that $81 \%$ of the changes in consumer spending on red meat are due to the shown independent factors. This has proven the statistical significance of the estimated model at the level of significance 0.01 where the calculated value of $(F)$ reached about 121.

\section{Recommendations}

1- The study recommends that it is necessary to expand the production of red meat to ensure that it is available at affordable prices suitable for low-income consumers, by encouraging the raising, production and fattening of calves, working to improve high-yield calves genetically, to ensure increased red meat production.

2- The necessity of working to encourage calves breeders and provide them with feed at reasonable prices, which leads to increased production of red meat.

\section{References}

Central Agency for Public Mobilization and Statistics, Annual Statistical Book, Various Editions

Hamdaoui, H. B., and S.A.A. Kamal, 2017. An Economic Study of Consumer Patterns in Urban and Rural Areas Sohag Governorate - the twenty-fifth conference of agricultural economists on (12) of November.

Jehan, R. L.M., 2001. An Economic Study of a Food Consumption Pattern in Egypt, Ph.D. Thesis, Department of Agricultural Economics, Faculty of Agriculture, Ain Shams University.

Ministry of Agriculture, Economic Affairs Sector, Central Administration for Agricultural Economics, Agricultural Economy Publications - various publications.

Ministry of Agriculture, Economic Affairs Sector, Central Administration for Agricultural Economics, Food Balance bulletins - various publications. 